ISSN: 2707-756X

DOI: $10.32996 /$ jeltal

Journal Hompage: www.al-kindipublisher.com/index.php/jeltal

\title{
Move Analysis of letters of Recommendation Written by Lecturers in a Ghanaian University
}

Joseph Benjamin Archibald Afful ${ }^{1}$ and Emmanuel Kyei*2

${ }^{1}$ PhD, Department of English, Faculty of Arts, University of Cape Coast, Ghana

${ }^{2}$ Tutor, Department of Languages, S. D. A. College of Education, Agona-Ashanti

Corresponding Author: Emmanuel Kyei, E-mail: okyekye09@gmail.com

\section{ARTICLE INFORMATION ABSTRACT}

Received: November 12, 2020

Accepted: December 15, 2020

Volume: 2

Issue: 5

DOI: 10.32996/jeltal.2020.2.5.1

\section{KEYWORDS}

Genre, letters of

recommendation, move

structure, communication

purpose(s), occluded
The scholarship on the rhetoric of letters of recommendation (LRs) has tended to cover those from the Anglo-American and European context. The present study aimed to investigate the structural organization of the LRs through an examination of the moves. The data consisted of purposively sampled 24 LRs written for candidates seeking admission into postgraduate programmes. The quality content analysis of the data complemented by some descriptive statistics showed that the LRs were characterized by a five-move structure: purpose of writing (move 1), context of knowing the candidate (Move 2), candidate's credentials (Move 3), candidate's personal values (Move 4), and closure (Move 5). In addition, with regard to the sequence of moves, the study found: (1) that the 5-move sequence was the most frequently used; (2) that the LRs mostly began with Move 1 ; (3) that the 1->3->3 sequence occurred most frequently; and (4) that Move 5 always occurred at the end of the UEW LRs. As regards the textual space of moves, it was found that Move 3, Candidate's credentials, occupied the greatest space (i.e. $53.01 \%$ ) in the LRs. Finally, the study implies that, while critical individual preferences exist in style, conventions of writing LRs are typically embedded in epistemological structures that are unique to the discipline. The present study has implications for the existing scholarship on LRs, EAP pedagogy and further research.

\section{Introduction}

Over the last three decades, genre studies have received great attention in several fields such as Applied Linguistics, Discourse Analysis, and Communication Studies. This growing interest in genre studies can be appreciated, given that genres present unique understanding into the nature of writing in both academic and other professional contexts. Afful (2005), for instance, contends that the genre-based approach to writing aids writers and English for Specific Purposes (ESP) practitioners, and effectively ushers them (writers and practitioners) into the academic community. Afful's view suggests that the use of the genre-based approach in text analysis can be a suitable resource in the design of ESP materials in general and EAP in particular.

Swales and Feak (2000) stressed that genres tend to form networks and presented a diagram comprising two genre 'networks'. They termed the first network, a representative sample of "open" genres which referred to those "that are public, often published, and easily visible or audible" (p. 8) and normally appear on a researcher's curriculum vitae (CV). Some of these genres include: conference abstracts, conference papers and other talks, research articles (RA), conference posters, theses and dissertations, technical reports, and books and monographs. Swales and Feak termed the second network, the "supporting genres" in that they assist or support an academic or research career. To a large extent, these genres have remained "hidden" or "closed" because they are not in the public domain (p. 9). These genres include: job applications, CV, job interviews, job talks, and submission letters.

K C AL-KINDI CENTER $\mathbf{R}$ D FOR RESEARCH Your gatewoy to world-class resecrch
Published by Al-KindiCenter for Research and Development. Copyright (c) the author(s). This is an open access article under CC BY license (https://creativecommons.org/licenses/by/4.0/) 
In the 1980s-1990s, as Swales and Feak (2000) explain, ESP research tended to focus on public or "open" genres, which are easily accessible, such as the research article (RA). In 1996, however, Swales investigated less public genres ("occluded" genres) that operate to support the research process. Swales (1996) explained that "occluded" genres are "typically hidden, 'out of sight' or 'occluded' from the public gaze" (p.46) and function to support the research process. He added that occluded academic genres "operate to support and validate the manufacture of knowledge, directly as part of the publishing process itself, or indirectly by underpinning the academic administrative processes of hiring, promotion and departmental review" ( $p$. 46). Among the genres that are typically 'out of sight' or 'occluded' from the public view by "a veil of confidentiality" (p. 46) is letters of recommendation (LRs). Even though a LR is part of the texts written for a small-group audience (in this case, the admission committee in an academic department), it does not only form part of a genre system that establishes a discipline's culture but also provides a gate-keeping role for entry into the academic discourse community.

LRs have gained scholarly interest, resulting in some studies in this field. Some of these studies (e.g. Adam-Moses, 2018; Bouton, 1995; Precht, 1998; Liu, 2007) have concluded that LRs have three main parts (introduction, body, and conclusion). Other studies (e.g. Madera, Hebl \& Martin, 2009; Schmader, Whitehead \&Wysocki, 2007; Trix \& Psenka, 2003) have found that male recommenders differed greatly from female recommenders and that LRs for female candidates tended to differ in terms of the linguistic resources employed. Colarelli, Hechanova-Alampay and Canali (2002) also investigated the appeal and tone of LRs and revealed that the cooperative relationship between recommenders and applicants favourably influenced the length of letters. More interestingly, Akos and Kretchmar (2016) analyzed LRs written by teachers for undergraduate applicants at a public university in the U.S. and found that the length of letters varied significantly with respect to the total word count according to the recommender 's gender and course type. They concluded that female recommenders appeared to write letters longer than male recommenders, and that LRs written by teachers of Humanities were longer than those written by teachers of Math/Science. Though LRs have received some attention, a common limitation is that none of these available studies applied genre analysis (move structure classification). A move structure classification, as Dudley-Evans (2000) points outs, provides a much broader view of the rhetorical organisation and lexico-grammatical resources in the genre. Afful (2018) employed genre analysis but the fact that he considered grant LRs written for research support provides a gap which the present study seeks to fill. It is, hence, essential to investigate LRs intended for postgraduate admission written by lecturers of a Ghanaian public institution for theoretical, pedagogical and professional reasons. In this study, therefore, our attention is directed towards the move structure of LRs in terms of frequency of occurrence, the textual space, and sequence of the moves which have been largely unattended to by the previous studies. The current study aims at analyzing LRs written by lecturers from the University of Education, Winneba, Mampong Campus. Specifically, the following research question is asked:

1. What move structure characterised the LRs written by lecturers from the University of Education, Winneba, Mampong Campus?

\section{Data source, analytical framework and procedure of analysis}

This study made use of twenty-four (24) LRs written by lecturers from the University of Education, Winneba, intended for admission into graduate programmes in the College of Agriculture Education, Mampong-Ashanti. Although this sample appears small, the study is still worthwhile in that linguistic studies do not require large samples since small samples can provide information that is representative of the broader reality (Mestherie, Swan, Deumart \& Leap, 2000). Hyland (2005) is also of the view that few texts with more detailed and specific analysis of the text samples is sufficient. Purposive sampling was used, enabling the selection of LRs written within the last five years (i.e. 2015-2019) and intended for prospective postgraduate studies. The letters were scanned and converted to Microsoft Word format.

Given the objective of the study, the ESP Approach of the Genre Theory was adopted. This study considered the definitions by Swales (1990) and Bhatia (1993) that a move is a cognitive-semantic unit linked to the purpose of the writer and relates to the overall function of the genre, while a step is defined in terms of a small unit of move. According to Bhatia (1993), the move structuring is the property of the genre itself, not something that the reader constructs. This structure is influenced by the communicative purpose(s) of the text, which is the underlying reason why one genre differs from another. Genre scholars (for example, Afful, 2005) have affirmed that the key concern of the move structure classification to text analysis is to classify the rhetorical structure of a genre in relation to its communicative purpose, while at the same time paying attention to the social context in which it takes place. Accordingly, this study's analytical approach was primarily to define the moves used to realize the communicative purpose(s) of the texts after which the linguistic resources used in the realization of these moves were analysed. The study employed the qualitative research design mainly because the analysis was more descriptive in 
nature although frequency counts are also employed in determining the frequency of occurrence, textual space, and sequence of moves that were identified in the data. The LRs were coded as DS 1, DS 2 ... DS 24.

\section{Findings and Discussion}

We discuss the move structure of the LRs written by some lecturers from the UEW, Mampong Campus, in terms of the description of the moves/steps in the data, frequency of occurrence of the moves/steps, the sequence of the moves/steps, the textual space allocated to each of the moves and the linguistic resources.

3.1 Description of Moves/Steps in the UEW Letters of Recommendation

Figure 1 presents the various moves/steps found in the LRs written by lecturers from the UEW, Mampong Campus.

\begin{tabular}{|c|c|c|c|}
\hline Moves & Steps & Name of Move & Name of Step \\
\hline Move 1 & & Purpose of writing & \\
\hline Move 2 & & Context of knowing the candidate & \\
\hline Move 3 & & Candidate's credentials & \\
\hline
\end{tabular}

\begin{tabular}{|c|c|c|c|}
\hline \multirow{10}{*}{$\begin{array}{l}\text { Move } 4 \\
\text { Move } 5\end{array}$} & Step 3.1 & & Academic achievement \\
\hline & Step 3.2 & & Relevant skills and abilities \\
\hline & Step 3.3 & & Classroom performance \\
\hline & Step 3.4 & & Co-curricular activities \\
\hline & & Candidate's personal values & \\
\hline & & Closure & \\
\hline & Step 5.1 & & Offering strong recommendation \\
\hline & Step 5.2 & & Expressing hope \\
\hline & Step 5.3 & & Soliciting response \\
\hline & Step 5.4 & & Ending politely \\
\hline
\end{tabular}

Figure 1: Description of Moves/Steps in the UEW Letters of Recommendation

As can be seen in Figure 1, the analysis of the data showed that LRs written by lecturers from the UEW, Mampong Campus, (totaling, 3,605), were characterised by a five-move structure: purpose of writing (move 1), context of knowing the candidate (Move 2), candidate's credentials (Move 3), candidate's personal values (Move 4), and closure (Move 5). Move 3 had four steps: academic achievement, relevant skills and abilities, classroom performance, and co-curricular activities. Move 5 had four (4) steps: offering strong recommendation, expressing hope, soliciting response, and ending politely. Moves 1, 2, and 4 had no steps. These moves/steps are discussed in the subsequent sections.

\section{Move 1: Purpose of Writing}

This move indicates that the writer knows the applicant, institution and programme he/she is applying for. This move, thus, states the reason for writing the letter. Some examples include the following:

1. I am thrilled to have the privilege of recommending to you BBB. -

(DS 2).

2. It delights me to recommend CCC for admission to pursue Master in Environmental Science and Occupational Health Education in your prestigious institution. - (DS 3)

3. It gives me immense pleasure to recommend EEE to your reputable institution. - (DS 5)

As noted from the examples above (1-3), writers here explain the reason they are writing: to recommend the candidate for the programme. Precht (1998) considers stating the purpose as a type of advance organizer, in that it gives advance notice to the reader of the order of topics to be discussed, or gives other signals to the reader of text organization. In the LRs of the UEW, announcing the letter's purpose was conveyed using words such as recommend (nine letters), support (four letters), my support (two letters) and of recommendation (one letter). The analysis of the LRs written by lecturers from the UEW, Mampong Campus, concurs with Bruland (2009) that "recommend" was predominantly used in stating the purpose of writing, while "support" was the second most frequently used word in announcing the writers' purpose.

\section{Move 2: Context of Knowing the Candidate}

Move 2 states the writer's relationship with the candidate. It mentions how long the writer has known the candidate, how the writer has known him (e.g. as a former student or friend) and other related details, as in the following: 
4. I have been closely associated with him since he became a member of the church and has risen through the church leadership ranks to the current rank as an Elder. -

5. I have known CCC since 2003 in my capacity as Senior Lecturer in the Department of Interdisciplinary Studies of the University of Education, Winneba, Kumasi campus, where he obtained Diploma in Education Certificate. I taught him Instructional Methods in Specified subjects and supervised his off-campus Teaching Practice.

6. I have worked very closely with DDD for four (4) years since he was employed as an Agricultural Science Tutor/Quality Assurance Coordinator in NJA College of Education. - (DS 4)

It can be observed from the examples above (4-6) that this move describes the relationship between the referee and the candidate which makes the writer a credible source. In Example 4 above, the writer indicates that he/she has known the candidate as a church member, and that the candidate has risen through the church leadership ranks to the rank of an Elder. In Example 5 above, the writer has known the candidate as a former student, and, in Example 6, the candidate was the writer's colleague. Example 6 above suggests that the writer, before being employed in the UEW, Mampong Campus, was in the same College of Education (i.e. NJA College of Education) with the candidate. Examples 4-6 above affirm Colarelli, Hechanova-Alampay and Canali's (2002) finding that, because writers are acquaintances of applicants, the tone of LRs reflects the degree of the relationship with the applicant. Providing specific contexts of knowing the applicant, as noted in Examples 4-6 above, was necessary given that LRs with specific examples of the degree of the relationship with the applicant, were evaluated more positively than those without examples (Knouse, 1983).

\section{Move 3: Candidate's Credentials}

Move 3 (Candidate's Credentials) provides details of the candidate's academic or professional history. Other details such as the candidate's programme offered, degree earned, class obtained, grades, honours and award(s) received are also provided. All the information in Move 3 concerned the academic identity of the recommendee (Akoto, 2018). In the UEW data collected, four (4) steps were found in this "Move". These steps are: academic achievement, relevant skills and abilities, classroom performance, and co-curricular activities. These four realisations of "Candidate's credentials" are discussed below:

\section{Step 3.1: Academic achievement}

This step mentions the candidate's programme of study, course(s) taken, class obtained, and a description of his/her academic capacities. This step demonstrates the candidates' academic preparedness for the proposed study. Some examples found in the UEW data are:

7. AAA was enrolled for the BSc. Environmental Health and Sanitation Education of University of Education, Winneba, Mampong Campus, Ashanti Region, and completed in 2014. He was always serious with his academic work and other responsibilities assigned to him while in school. He worked diligently and consistently to prove his abilities. (DS 1)

8. He is a graduate of both University for Development Studies, Tamale, and University of Education, Kumasi Campus, Winneba, where he obtained his Bachelor's degree in Applied Biology and Diploma in Education respectively. - (DS 2)

9. Academically, he is very good and could be found in the top $10 \%$ of his class. Also, CCC is capable of doing independent studies and research and therefore has the capacity to meet the challenges usually associated with graduate studies. - (DS 3)

10.

The examples above (7-9) generally illustrate attempts to provide specific academic qualities of the candidates. In Example 7 above, the writer provides specific details related to the academic life of the candidate, such as "serious with his academic work and other responsibilities assigned to him" and "worked diligently and consistently". In Example 8, the writer adds the candidate's programme (s) of study, and in Example 9, the writer provides information about the candidate's academic performance compared with his classmates.

\section{Step 3.2: Relevant skills and abilities}

This step mentions the candidate's written (or spoken) language abilities, skills, etc. Here are examples:

10. His English Language, both spoken and written is flawless. CCC exhibits a good sense of maturity, possesses high quality of initiative and demonstrates good leadership qualities. - (DS 3)

11. He demonstrated excellent organizational skills. His ability to lead successfully was shown each time he volunteered to be team leader of class group and he was able to solve any problems encountered quickly and effectively while listening to others. He has excellent analytical, mathematical, technical, and computer skills. - (DS 5) 
12. He has a very good team building skills. - (DS 6)

The above examples (10-12) attempt to provide significant skills and abilities of the candidates. In Example 10, the recommender evaluated relevant skills and abilities related to the candidate's communication, critical thinking, and leadership skills. In Example 11, the candidate's organizational skills, listening skills, critical thinking skills, leadership skills, and other academic abilities necessary for his proposed programme of study were evaluated. In Example 12, the writer positively evaluated the applicant's team building skills.

\section{Step 3.3 Classroom performance}

The third step in this move was "Classroom performance". This step mentions the candidate's score, overall classroom behaviour, learning, and evaluation of what the writer observed about the candidate in class. This step reflects what the writer observed, actually saw and evaluated during his/her lecture time with the candidate. In some of the letters, the writers indicated what they observed while they supervised the candidate's project work. Find examples as follows:

13. He has an exceptional creative competence and capable of doing independent work and research. - (DS 1)

14. As his lecturer, I taught him Information Communication Technology and supervised his project. He could be found in the top 10 of his class. - (DS 5)

15. I was privileged to teach and supervise his project work. I often found him in the library looking for other similar studies done to enhance his understanding of the subject matter. During that project, LLL demonstrated his ability to work independently with creativity and enthusiasm. - (DS 12)

In the examples above (13-15), the authors have evaluated what they observed about the candidates with regard to their (the candidates') classroom behaviours. In Example 13 above, the recommender mentions the candidate's excellent classroom behaviours, to suggest his readiness to successfully undertake the proposed programme of study. For instance, the recommender stressed his "exceptional creative competence" and his ability to do independent work/research. In Example 14 above, the recommender rated the applicant as one of the best students in class. This evaluation is possible because the recommender has not only taught the recommendee, but also supervised his project work. One key fact is that the writer's evaluation can be verified on the transcript of the recommendee or even in the records of the institution. Similarly, Example 15 suggests that the writer taught the candidate and supervised his project work, providing a reliable ground to evaluate his (the applicant's) classroom performance. Examples 13-15 above, thus, indicate that all the evidences provided were based on the self-experiences of the recommenders.

\section{Step 3.4: Co-curricular activities}

This step mentions some co-curricular activities that the applicant participated in. The author mentions these activities to demonstrate the applicant's ability to engage in other activities aside the curricular ones, and his/her ability to influence others. Examples include the following:

16. He seeks advice and information from his superiors and authorities as a way of interaction. Apart from the routine classroom activities, he doubles as Parent-Teacher Association and staff secretary as well as basic schools examination co-ordinator in Anglican SHS.

Regards to co-curricular activities in the Basic School he holds the position of sports Secretary with much commitment that impacted discipline in the District so far as sporting activities are concerned. - (DS 8)

17. He has been of great help to the Guidance and Counseling co-coordinator in the school because he organizes career guidance lectures for students in the school. His lectures on career guidance have been clear and concise. - (DS 11)

18. She also took immense interest in extra-curricular activities during her studies. - (DS 17)

The examples (16-18) above provided information about the candidate's co-curricular activities. In Example 16, the writer mentioned that the applicant was "Parent-Teacher Association and Staff Secretary, as well as Basic Schools Examination Coordinator in Anglican SHS". The mention of "Anglican SHS" suggests that the author probably knew the applicant there or had worked with him, and that makes it easier for the applicant to "seek advice and information" from the author. In Example 17, the author indicated that the candidate was a "Guidance and Counseling Co-ordinator" where he organised and gave lectures on career guidance. In Example 18, however, the author generally evaluated the co-curricular activities of the applicant, and did not mention any specific co-curricular activity the applicant engaged in. This step, though not frequently employed by the 
UEW writers, suggests the candidate's teamwork capabilities and ability to influence others, which can give a positive impression to the admission committee. According to Liu (2007), outstanding students are not only expected to achieve high scores but are also supposed to be enthusiastic, active, and talented in co-curricular activities such as sports and art performances.

\section{Move 4: Candidate's Personal Values}

The UEW writers also provided some positive personal characteristics of the applicant, including his/her integrity, ethics, motivation, honesty, leadership skills, and his/her strengths. These are some examples:

19. He has a likeable personality which enables him to work well in a group. He has a very good team building skills. I have found him to be highly disciplined person, intelligent, level headed, hardworking and well organised. - (DS 1)

20. He has a servant heart and excellent work ethics, a warm personality, mixes well with people and a good team player. - (DS 2)

21. He has excellent personality, character and creativity. He is humble, honest, hardworking and relates very well with his colleagues and lecturers. - (DS 7)

In the examples above (19-21), the UEW writers detailed the candidate's personal characteristics, such as integrity, ethics, motivation, honesty, dependability, and reliability. In Example 19 above, the author focused on personal characteristics of the candidate (such as "disciplined person", "intelligent", "level headed", "hardworking", and "well organised"), deemed to be relevant to the application. Similarly, in Example 20, the writer mentioned the applicant's positive personal traits such as "excellent work ethics", "warm personality", "mixes well with people", and as a "good team player". In the same vein, the author in Example 21 added the candidate's positive personal characteristics such as "humble", "honest", "hardworking", and "relates very well with his colleagues and lecturers".

All these positive personal traits (as indicated in 19-21 above) lead to success in a workplace or in a chosen field of study. As Aamodt, Bryan and Whitcomb (1993) found, these traits are not only reliable but also valid predictors of future performance.

\section{Move 5: Closure}

The UEW concluded their LRs with the last move, closure. This move had four (4) steps: "offering strong recommendation," "expressing hope," "soliciting response," and "ending politely". These four (4) instantiations of the last move, closure, are discussed below:

\section{Step 5.1: Offering strong recommendation}

Here, the author shows his/her strong vote of support, and states explicitly his/her level of recommendation. Find examples below:

22. I have no doubt that AAA is sufficiently motivated to excel in any assignment entrusted to him. - (DS 1)

23. I, therefore, strongly recommend his application. - (DS 7)

24. I, therefore, without reservation recommend him for the programme. - (DS 10)

The examples above (22-24) illustrate a rhetorical pattern which provides a strong recommendation, aimed at making a deeper impression upon the reader(s) and possibly influence the decision-making. In Examples 22-24 above, the authors used the personal pronoun "I", evaluative lexis (such as "strongly recommend", and "have no doubt"), and boosters (e.g. "without reservation") to show their full commitment to the proposition. This finding affirms Afful's (2018) finding that grant LRs use evaluative lexis and personal pronoun, as well as Akoto's (2018) finding that boosters and attitude markers are used in LRs.

\section{Step 5.2: Expressing hope}

Here, the writers show strong and positive beliefs and hopes in the candidate. This step shows that the writer is certain that the candidate will succeed in his/her proposed graduate studies. Find examples as follows:

25. I have no doubt that AAA is sufficiently motivated to excel in any assignment entrusted to him. - (DS 1)

26. I have no doubt whatsoever of CCC's ability to do excellent academic and research work. - (DS 3)

27. There will be no unpleasant surprises and I am confident he will fit in and surpass your expectations in the Master of Philosophy in Animal Science (Non-Ruminant Nutrition) programme he is seeking admission for. - (DS 4) 
Examples 25-27 above illustrate a step in the closure which provides a prediction of the candidate's future success. In Examples 25-27 above, the UEW authors express confidence and hope in candidates, and make it clear that the candidates will succeed in the proposed programmes of study. Examples 25 and 26 above illustrate the structure the UEW writers preferred to follow, i.e. the use of the first person pronoun "I", with the verb "have" and "no doubt", as in "I have no doubt," or with the verb "be" plus the adjective "confident", (as in "I am confident" in Example 27), to express belief in the future success of the recommendee.

Step 5.3: Soliciting response

This step invites the reader to contact the writer for any further information or enquires on the applicant. See examples as follows:

28. Please do not hesitate to contact me for any clarification if need be. - (DS 2)

29. Please feel free to contact me if you have any questions about this outstanding young man at (+233>0268xxxxxx036/ +233>039209xxxx or sksssssssdddsalih@yahoo.com.-(DS $\underline{4)}$

30. Please contact me if you have any questions about PPP on +233xxxxxxxx or assssssssss@yahoo.com. - (DS 16)

The examples above (28-30) illustrate a rhetorical pattern in the closure that invites the reader(s) to freely contact the writer in case of anything. In Examples 29 and 30, the authors provide their email addresses or phone numbers, and request the reader(s) to contact them for further service. As noted from Examples 28-30 above, the UEW authors often employed the polite imperative sentences, and often began with please plus the bare form of the verb e.g. do, feel and contact. In the words of Bruland (2009), this provides an offer on the part of the recommender to be of further service. According to Ebadi and Saedidovaise (2015), this offer for contact makes the appeal for consideration of the applicant seem more serious for the reader.

\section{Step 5.4: Ending politely}

The UEW writers often ended the letter on a polite note. "Thank you" was preferred in the LRs written by faculty from the UEW, Mampong Campus.

\section{Sample of a Letter of Recommendation}

In the section below, we present a move analysis of an unedited UEW LR. The sample data was coded DS 2 . The results are presented in Figure 2.

\begin{tabular}{lc}
\hline DS 2: The original LR & Move/Step \\
\hline I am thrilled to have the privilege of recommending to you BBB. & Move 1 \\
He is a graduate of both University for Development Studies, Tamale and University \\
of Education, Kumasi Campus, Winneba where he obtained his Bachelor's degree in \\
Applied Biology and Diploma in Education respectively. & Move 3/Step 1 \\
BBB has been long-term member of the Church Christ Cosmopolitan Incorporated. I & Move 2 \\
have been closely associated with him since he became a member of the church & Move 4 \\
and has risen through the church leadership ranks to the current rank as an Elder. & Move 5/Step 2 \\
He has a servant heart and excellent work ethics, a warm personality, mixes well & \\
with people and a good team player & Move 5/Step 1 \\
I believe in him & Move 5/Step 3 \\
and want to highly recommend him for admission into your institution to undertake \\
the programme for which he has applied. \\
$\begin{array}{l}\text { Please do not hesitate to contact me for any clarification if need be. } \\
\text { Thank you. }\end{array}$
\end{tabular}

Figure 2: Move analysis of a Sample Unedited UEW LR 
Figure 2 illustrates that the DS 1 was characterised by a five-move structure. In the sample above, the writer indicated his/her delight in writing to recommend the candidate for further studies. Then, the writer provided the candidate's academic achievements. After the writer established the candidate's credentials, the next Move realized was providing the context of knowing the candidate. It can be deduced from the sample above that the writer knew the candidate as a church member. Next, the writer provided the candidate's personal values, and then the closure. It can be argued that the writer's stylistic preference could explain why he/she included only step 1 (academic achievement) of Move 4 (candidate's credentials). Similarly, the writer preferred all the four steps of Move 5 (closure). This means that all the four steps in the Move 5: "offering strong recommendation," "expressing hope," "soliciting response," and "ending politely" were realized in the UEW LR analysed.

In the next section, I analyse and discuss the frequency of occurrence of moves/steps in the LRs written by lecturers from the UEW, Mampong Campus.

\subsection{Frequency of Occurrence of Moves/Steps in UEW Data}

The study sought to investigate the frequency of occurrence of moves/steps in the LRs written by faculty from the UEW, Mampong Campus. The results are presented in Table 1.

Table 1: Frequency of Moves/Steps in UEW Data

\begin{tabular}{|c|c|c|c|c|}
\hline Moves & Description of Moves & $\begin{array}{l}\text { Steps } \\
\text { Description }\end{array}$ & $\begin{array}{l}\text { Frequencies of } \\
\text { Occurrence } \\
\mathrm{N}=24\end{array}$ & $\begin{array}{l}\% \text { of } \\
\text { Occurrence }\end{array}$ \\
\hline 1. & Purpose of writing & & 16 & 66.67 \\
\hline 2. & $\begin{array}{l}\text { Context of knowing the } \\
\text { candidate }\end{array}$ & & 15 & 62.50 \\
\hline \multirow[t]{5}{*}{3.} & Candidate's credentials & & 22 & 91.67 \\
\hline & & 1. Academic achievement & 21 & 87.5 \\
\hline & & 2. Relevant skills and abilities & 10 & 41.67 \\
\hline & & 3. Classroom performance & 9 & 37.50 \\
\hline & & 4. Co-curricular activities & 3 & 12.50 \\
\hline 4. & Candidate's personal values & & 17 & 70.83 \\
\hline \multirow[t]{5}{*}{5.} & Closure & 1. Offering strong & 24 & 100 \\
\hline & & recommendation & 17 & 70.83 \\
\hline & & 2. Expressing hope & 15 & 62.50 \\
\hline & & 3. Soliciting response & 3 & 12.50 \\
\hline & & 4. Ending politely & 5 & 20.83 \\
\hline
\end{tabular}

$100 \%=$ Moves occurred in all UEW LRs

Table 1 illustrates that the move, Closure had the highest percentage of the frequency of occurrence at $100 \%$, followed by the move, Candidate's credentials which had 22 occurrences, representing 91.67\%. The step, academic achievement, had $87.50 \%$. Both Candidate's personal values and offering strong recommendation had 17 occurrences, indicating $70.83 \%$. Move 1, Purpose of writing, occurred in 16 (66.67\%) out of the 24 UEW LRs, whereas both the move, Context of knowing the candidate, and step, expressing hope, showed the percentage of the frequency of occurrence at $62.50 \%$. The step, relevant skills and abilities, had the frequency of $10(41.67 \%)$. The step, classroom performance, had the frequency of 9 , representing $37.50 \%$, whereas the step, ending politely, had 5 occurrences, representing $20.83 \%$. Finally, the steps of co-curricular and soliciting response had 3 occurrences, representing $12.50 \%$ each. The analysis above concurs with Precht (1998), who found that all the British LRs had predictions, also referred to as conclusion (Ebadi \& Saedidovaise, 2015; Liu, 2007). The indication is that there are five (5) typical moves of LRs written by faculty of the UEW. This finding contrasts Liu's (2007) finding that a typical LR has four (4) moves: (1) Purpose, (2) Context of knowing, (3) Topicality and (4) Conclusion. The difference results from the fact that, while the present study considered the move, Candidate's personal values, Liu added it to the topicality.

Generally, the typical moves found in the LRs written by faculty in the UEW agree with the findings of Range, et al. (1991) that LRs normally indicate the writer's association with the applicant, the applicant's skills and ethics, interpersonal skills, supervision behaviour, and worthy accomplishments, and closing positive remarks. 


\subsection{Sequence of Moves in UEW Letters of Recommendation}

Sequencing of Moves is the order of Moves as they appear in a text. Table 2 below shows the order of the Moves in the LRs written by faculty from the UEW, Mampong Campus.

Table 2: Sequencing of Moves in the UEW Data Set

\begin{tabular}{|c|c|c|c|c|}
\hline Kind & Pattern & Frequency & Total & $\%$ \\
\hline \multirow[t]{3}{*}{1} & 9-move sequence & & 2 & 8.33 \\
\hline & 1->2->4->3->3->3->5->5->5 & 1 & & \\
\hline & 1->2->3->3->3->4->5->5->5 & 1 & & \\
\hline \multirow[t]{2}{*}{2} & 8-move sequence & & 1 & 4.17 \\
\hline & $1->3->3->2->4->5->5->5$ & 1 & & \\
\hline \multirow[t]{6}{*}{3} & 6-smove sequence & & 7 & 29.17 \\
\hline & $1->2->3->4->3->5$ & 1 & & \\
\hline & $2->3->3->2->3->5$ & 1 & & \\
\hline & $1->3->3->4->5->5$ & 3 & & \\
\hline & $3->1->3->3->5->5$ & 1 & & \\
\hline & $2->1->3->4->5->5$ & 1 & & \\
\hline \multirow[t]{8}{*}{4} & 5 move sequence & & 9 & 37.50 \\
\hline & $3->4->3->5->5$ & 2 & & \\
\hline & $3->2->3->5->5$ & 1 & & \\
\hline & $2->3->4->5->5$ & 1 & & \\
\hline & $2->1->3->3->5$ & 2 & & \\
\hline & $1->2->3->4->5$ & 1 & & \\
\hline & $2->1->3->4->5$ & 1 & & \\
\hline & $1->2->3->4->5$ & 1 & & \\
\hline \multirow[t]{6}{*}{5} & 4-move sequence & & 5 & 20.83 \\
\hline & $2->4->5->5$ & 1 & & \\
\hline & $3->4->3->5$ & 1 & & \\
\hline & $2->3->3->5$ & 1 & & \\
\hline & $3->4->3->5$ & 1 & & \\
\hline & $1->3->3->5$ & 1 & & \\
\hline Total & & 24 & 24 & 100 \\
\hline
\end{tabular}

As can be seen in Table 2, the analysis revealed five (5) different patterns in the LRs written by lecturers from the UEW. The ordering of the Moves ranged from a 4-move sequence to a 9-move sequence, but there was no 7-move sequence. Of all the different patterns, the most frequently used was the 5 -move sequence, and it occurred nine (9) times, indicating $37.50 \%$. The second most frequently employed was the 6 -move sequence, with 7 (29.17\%) occurrences, while the third most frequently employed was the 4-move sequence, and it occurred five (5) times (i.e. 20.83\%). 10 (41.67\%) of the LRs written by faculty from the UEW began with Move 1. 8 (33.33) of the UEW, Mampong Campus, LRs also began with by Move 2, and 6 (25\%) began with Move 3. The analysis has revealed that Move 1 was mostly found introducing the UEW data set.

A careful observation of Table 2 also shows that the writers mostly used the 1->3-ı3 sequence, which occurred 5 times (i.e. $20.83 \%$ ), and was closely followed by the 1->2->3 sequence (i.e. 4, indicating $16.67 \%$ ). This finding implies that the UEW, Mampong Campus, authors preferred to begin with the purpose of writing, followed by establishing the candidature of the applicant. Closely related to this sequence, the UEW, Mampong Campus, authors could also begin with the purpose of writing, followed by the context of knowing the candidate, and then the candidate's credentials. Finally, a close observation of Table 2 shows that Move 5 had a constant position of occurring at the end of the data. This implies that Move 5 always maintained its position in all the data.

The analysis of the UEW, Mampong Campus, data set has revealed that some interesting findings: (1) that the 5-move sequence was the most frequently used; (2) that the UEW LRs mostly began with Move 1 ; (3) that the 1->3->3 sequence occurred most frequently; and (4) that Move 5 always occurred at the end of the UEW LRs. 


\subsection{Textual Space of Moves in UEW Letters of Recommendation}

The results, as presented in Table 3, show that Move 3, Candidate's credentials, occupied the most space in the LRs. It occupied more than half (53.01\%) of the data.

Table 3: Textual Space of Each Move in the UEW Data Set

\begin{tabular}{lllllll}
\hline Data & Move 1 & Move 2 & Move 3 & Move 4 & Move 5 & Total \\
\hline DE 1 & 0 & 0 & 76 & 38 & 28 & 142 \\
DE 2 & 12 & 30 & 43 & 21 & 30 & 136 \\
DE 3 & 22 & 47 & 66 & 22 & 33 & 190 \\
DE 4 & 0 & 64 & 0 & 99 & 57 & 220 \\
DE 5 & 12 & 27 & 115 & 64 & 23 & 241 \\
DE 6 & 0 & 0 & 94 & 22 & 28 & 144 \\
DE 7 & 18 & 28 & 39 & 21 & 6 & 112 \\
DE 8 & 0 & 0 & 111 & 0 & 13 & 124 \\
DE 9 & 0 & 0 & 57 & 0 & 35 & 92 \\
DE 10 & 0 & 13 & 11 & 55 & 30 & 109 \\
DE 11 & 0 & 9 & 106 & 0 & 20 & 135 \\
DE 12 & 0 & 22 & 104 & 0 & 13 & 139 \\
DE 13 & 0 & 26 & 0 & 82 & 23 & 131 \\
DE 14 & 13 & 0 & 97 & 0 & 18 & 128 \\
DE 15 & 18 & 22 & 102 & 0 & 14 & 156 \\
DE 16 & 14 & 0 & 114 & 20 & 26 & 174 \\
DE 17 & 16 & 0 & 132 & 0 & 17 & 165 \\
DE 18 & 14 & 17 & 88 & 23 & 8 & 150 \\
DE 19 & 18 & 16 & 56 & 19 & 7 & 116 \\
DE 20 & 12 & 0 & 109 & 19 & 28 & 168 \\
DE 21 & 15 & 21 & 106 & 0 & 18 & 160 \\
DE 22 & 22 & 0 & 116 & 23 & 33 & 194 \\
DE 23 & 13 & 28 & 62 & 20 & 8 & 131 \\
DE 24 & 13 & 14 & 107 & 0 & 14 & 148 \\
Total & $\mathbf{2 3 2}$ & $\mathbf{3 8 4}$ & $\mathbf{1 9 1 1}$ & $\mathbf{5 4 8}$ & $\mathbf{5 3 0}$ & $\mathbf{3 6 0 5}$ \\
& $\mathbf{( 6 . 4 4 \% )}$ & $\mathbf{( 1 0 . 6 5 \% )}$ & $\mathbf{( 5 3 . 0 1 \% )}$ & $\mathbf{( 1 5 . 2 0 \% )}$ & $\mathbf{( 1 4 . 7 0 \% )}$ & $\mathbf{1 0 0}$ \\
\hline
\end{tabular}

The results, as indicated in Table 3, illustrate that Candidate's credentials occupied the most space, i.e. 53.01\%. This was followed by Candidate's personal values (i.e. 15.20\%), and then Closure (i.e. 14.70\%). Context of knowing the candidate was the fourth and occupied $10.65 \%$, and finally, Purpose of writing which occupied the least space, $6.44 \%$. In terms of the relative space given to the Moves 4 and 5, the percentage for the UEW authors is about the same, at $15.20 \%$ and $14.70 \%$ respectively.

The finding that Candidate's credentials occupied the most space, affirms the view of Akoto (2018) that the writer needs to demonstrate that he/she knows the applicant academically, and, thus, provide enough textual space for the academic themes of the candidate. In the words of Afful (2018), the textual space allocated to Candidate's credentials, determines its importance.

\section{Conclusion}

The present study aimed to analyse twenty-four (24) LRs written by lecturers of the University of Education, Winneba, (UEW), Mampong Campus, for students intending to undertake postgraduate studies. Swales (1990) move analysis rhetorical approach was utilized together with a qualitative content analysis approach supplemented by simple frequency count. The analysis of the moves found that lecturers from the UEW, Mampong Campus, used a five-move structure, specifically: purpose of writing (move 1), context of knowing the candidate (Move 2), candidate's credentials (Move 3), candidate's personal values (Move 4), and closure (Move 5). In addition, with regard to the sequence of moves, the study revealed: (1) that the 5-move sequence was the most frequently used; (2) that the UEW LRs mostly began with Move 1 ; (3) that the 1->3->3 
sequence occurred most frequently; and (4) that Move 5 always occurred at the end of the UEW LRs. As regards the textual space of moves, it was found that Move 3, Candidate's credentials, occupied the most space (i.e. 53.01\%) in the LRs.

Through this analysis, we concluded that though critical individual differences exist in style, the conventions of writing LRs are generally rooted in epistemological structures which are often discipline specific. This key finding adds to the scholarship on letters of recommendation which had often and hitherto been limited to non-African context. In this wise, the findings widen the scope of the scholarship on the rhetoric of letter of recommendation

Given the small size of the sample further research can seek to cover other letters of recommendations from other public educational institutions in Ghana with the view to expanding the sample size. Another line of research may be conducted from the stance that communicative purpose may be inadequate in unearthing fully the rhetorical disposition of letters of recommendation. In this case, the register theory may be utilized to ascertain the lexico-grammatical resources by focusing on the ideational metafunction.

\section{References}

[1] Aamodt, M. G., Bryan, D. A., \& Whitcomb, A. J. (1993). Predicting performance with letters of recommendation. Public Personnel Management, 22(1), 81-90.

[2] Adam-Moses, K. (2018, July 30). On what and how: A rhetorical analysis of letters of recommendation of Ghanaian academics. Paper presented at the 11th Linguistics Association of Ghana Annual Conference (LAG 2018), Modern Languages Annex, University of Ghana, Legon, Accra. Retrieved from https://www.ug.edu.gh/linguistics/content/11th-linguistics-association-ghana-annualconference-lag-2018.

[3] Afful, J. B. A. (2005). A rhetorical analysis of examination essays in three disciplines: The case of Ghanaian undergraduate students[ Unpublished PhD thesis] National University of Singapore, Singapore.

[4] Afful, J. B. A. (2018, April 26). Rhetorical analysis of grant recommendation letters written by faculty in a Ghanaian university. Paper presented at the Department of Literature, Section for Rhetoric, and Department of English Conference, Uppsala, University, Sydney. Retrieved from http://www.kalendarium.uu.se/event/?eventld=34804.

[5] Akos, P., \& Kretchmar, J. (2016). Gender and ethnic bias in letters of recommendation: Considerations for school counselors. Professional School Counseling, 20(1), 1096-2409.

[6] Akoto, O. Y. (2018). Corpus-based exploration of 'professional ideologies' in letters of recommendation by academics. Manuscript submitted for publication.

[7] Bhatia, V. K. (1993). Analyzing genre: Language use in professional settings. Longman.

[8] Bouton, L. F. (1995). A cross-cultural analysis of the structure and content of letters of reference. Studies in Second Language Acquisition, 17(2), 211-244.

[9] Colarelli, S. M., Hechanova-Alampay, R., \& Canali, K. G. (2002). Letters of recommendation: An evolutionary psychological perspective. Human Relations, 55(3), 315-344.

[10] Dudley-Evans, T. (2000). Genre analysis: A key to a theory of ESP?. Ibérica, Revista de la Asociación Europea de Lenguas para Fines Específicos, (2), 3-11.

[11] Ebadi, S., \& Saedidovaise, M. (2015). A contrastive study of letters of recommendation in Persian and English. Journal of English Language and Literature, 3(1), 213-218.

[12] Hyland, K. (2005). Metadiscourse. London: Continuum.

[13] Knouse, S. B. (1983). The letter of recommendation: Specificity and favorability of information. Personnel Psychology, 36, 331-341.

[14] Liu, J. (2007). Intercultural communication in letters of recommendation. Journal of Intercultural Communication, 13. Retrieved August 20, 2018 from http://www.immi.se/intercultural.

[15] Madera, J. M., Hebl, M. R., \& Martin, R. C. (2009). Gender and letters of recommendation for academia: Agentic and communal differences. Journal of Applied Psychology, 94(6), 15-91.

[16] Mestherie, R., Swan J., Deumart, A. \& Leap, W. (2000). Introducing sociolinguistics. Edinburgh University Press.

[17] Precht, K. (1998). A cross-cultural comparison of letters of recommendation. English for Specific Purposes, 17(3), $241-265$.

[18] Schmader, T., Whitehead, J., \& Wysocki, V. H. (2007). A linguistic comparison of letters of recommendation for male and female chemistry and biochemistry job applicants. Sex Roles, 57(7-8), 509-514.

[19] Swales, J. (1990). Genre analysis: English in academic and research settings. Cambridge: University Press.

[20] Swales, J. (1996). Occluded genres in the academy. Academic Writing, 45-58.

[21] Swales, J. M., \& Feak, C. B. (2000). English in today's research world: A writing guide. Michigan: University Michigan Press.

[22] Trix, F., \& Psenka, C. (2003). Exploring the color of glass: Letters of recommendation for female and male medical faculty. Discourse \& Society, 14(2), 191-220. 